\title{
Experimental analysis of the effect of suction and step height on boundary-layer transition
}

\author{
Benjamin Dimond*, Marco Costantini, Christian Klein \\ * German Aerospace Center (DLR), E-Mail: benjamin.dimond@dlr.de
}

\section{Introduction}

Laminar flow on transport aircraft is challenging to maintain in the presence of surface imperfections such as steps and/or gaps, which can occur at structural joints. A substantial stream-wise delay of laminar-turbulent transition, however, can be achieved by suction. This work focuses on the influence of suction on transition in the presence of forward-facing steps (FFS) and backward-facing steps (BFS) (step Reynolds number $R e_{h}$ ) in combination with stream-wise gaps (gap Reynolds number $R e_{g a p}$ ). Systematic experimental investigations were performed in the low-turbulence Cryogenic Ludwieg-Tube Goettingen for large Reynolds numbers (chord Reynolds numbers up to $R_{c}=16 \cdot 10^{6}$ ), Mach numbers $0.35 \leq M \leq 0.77$ and various streamwise pressure gradients quantified by $\beta_{H}$ (Hartree parameter).

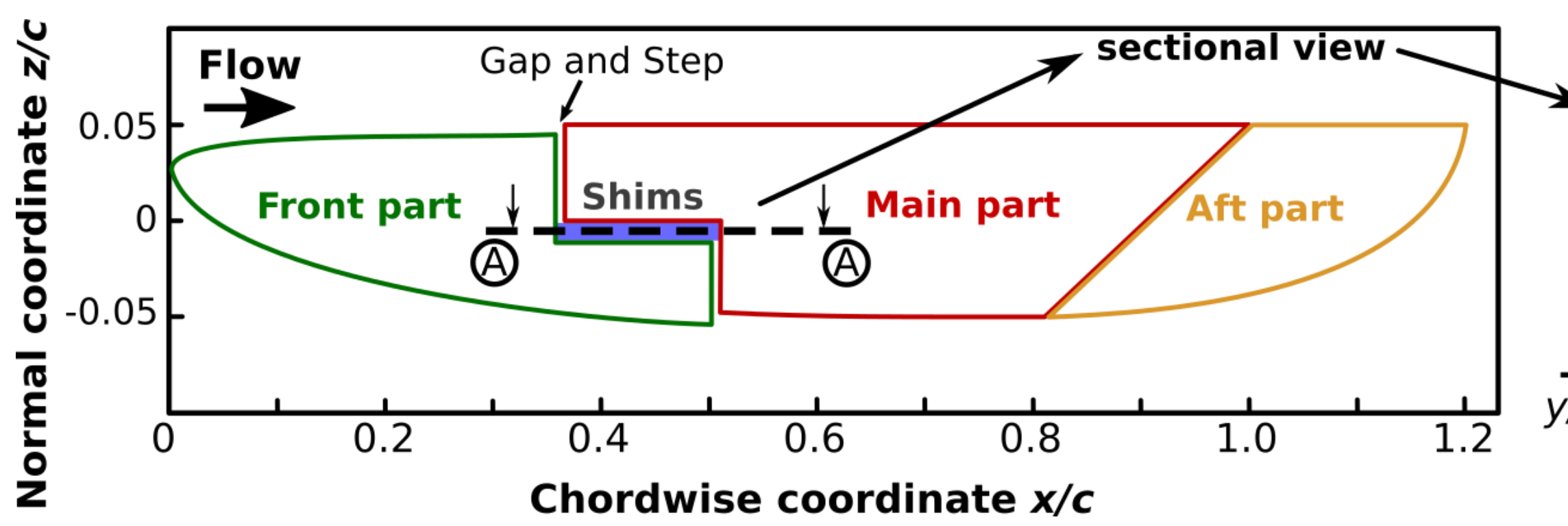

Simplified sketch of the wind-tunnel model. Left: cross-section Right: sectional view in the A-A plane.
- Chord length $c=200 \mathrm{~mm}$

- Additional aft part to reduce disturbances

- Temperature-sensitive paint (TSP) for transition detection

Passive suction through the gap driven by pressure difference between upper and lower side

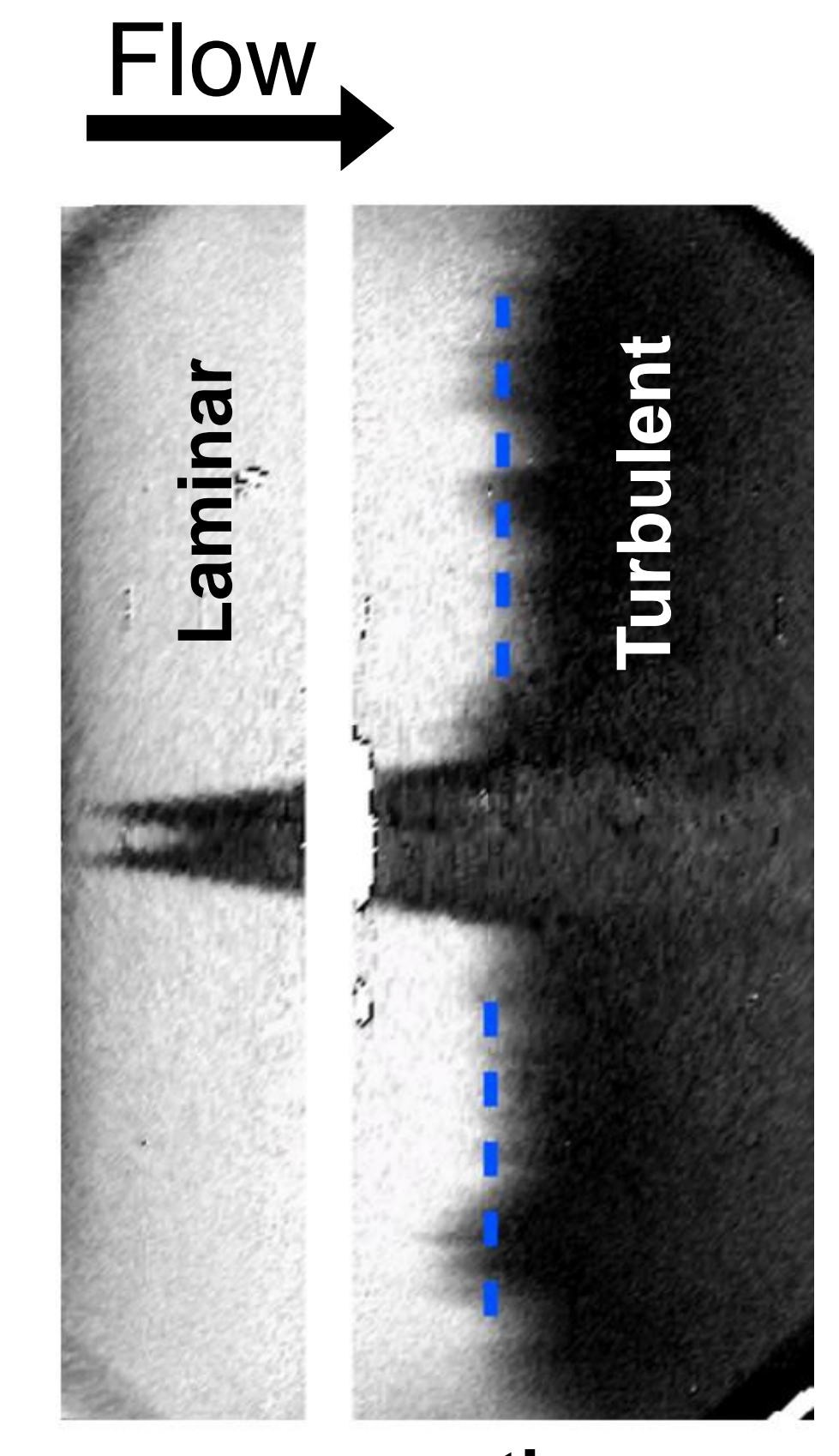

smooth (no suction)

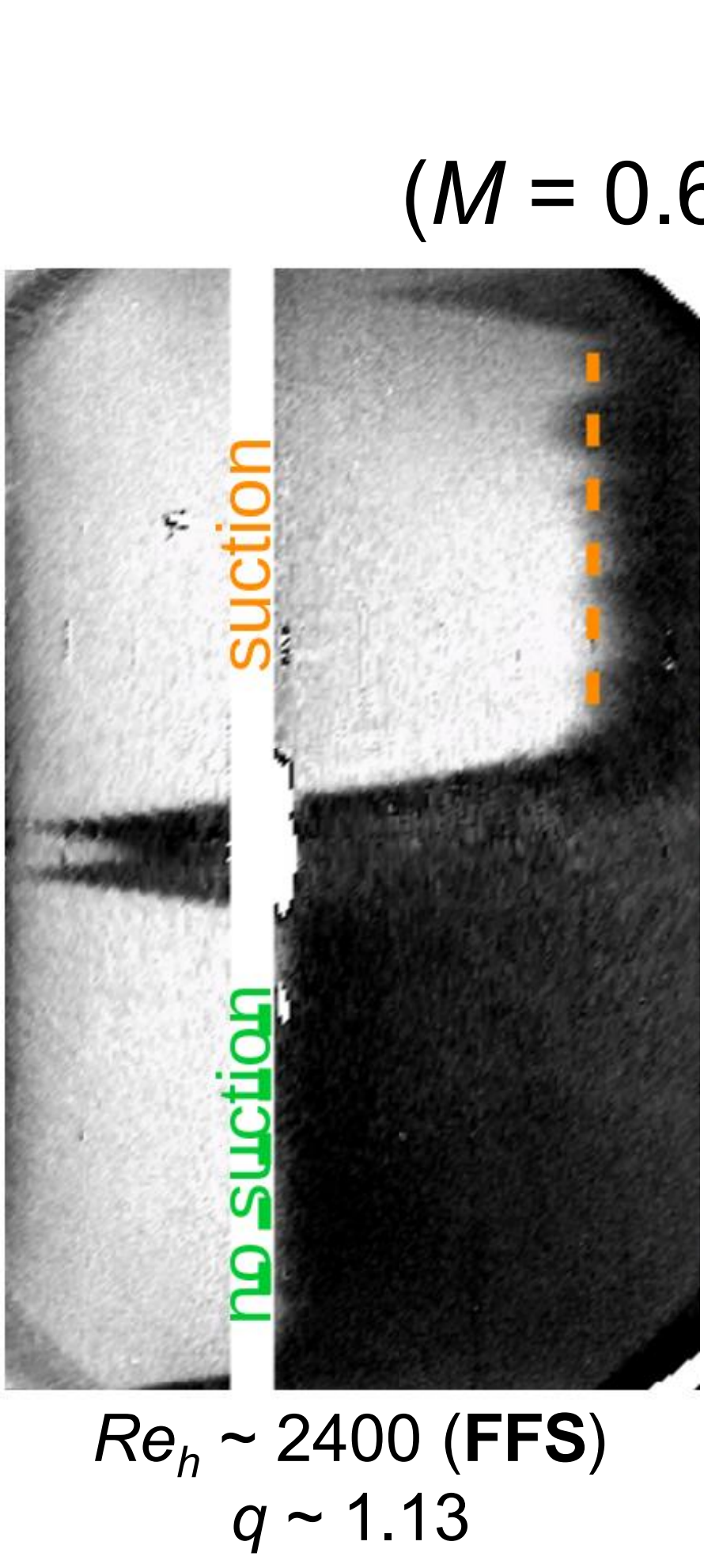

$q \sim 1.13$

\section{TSP Results}

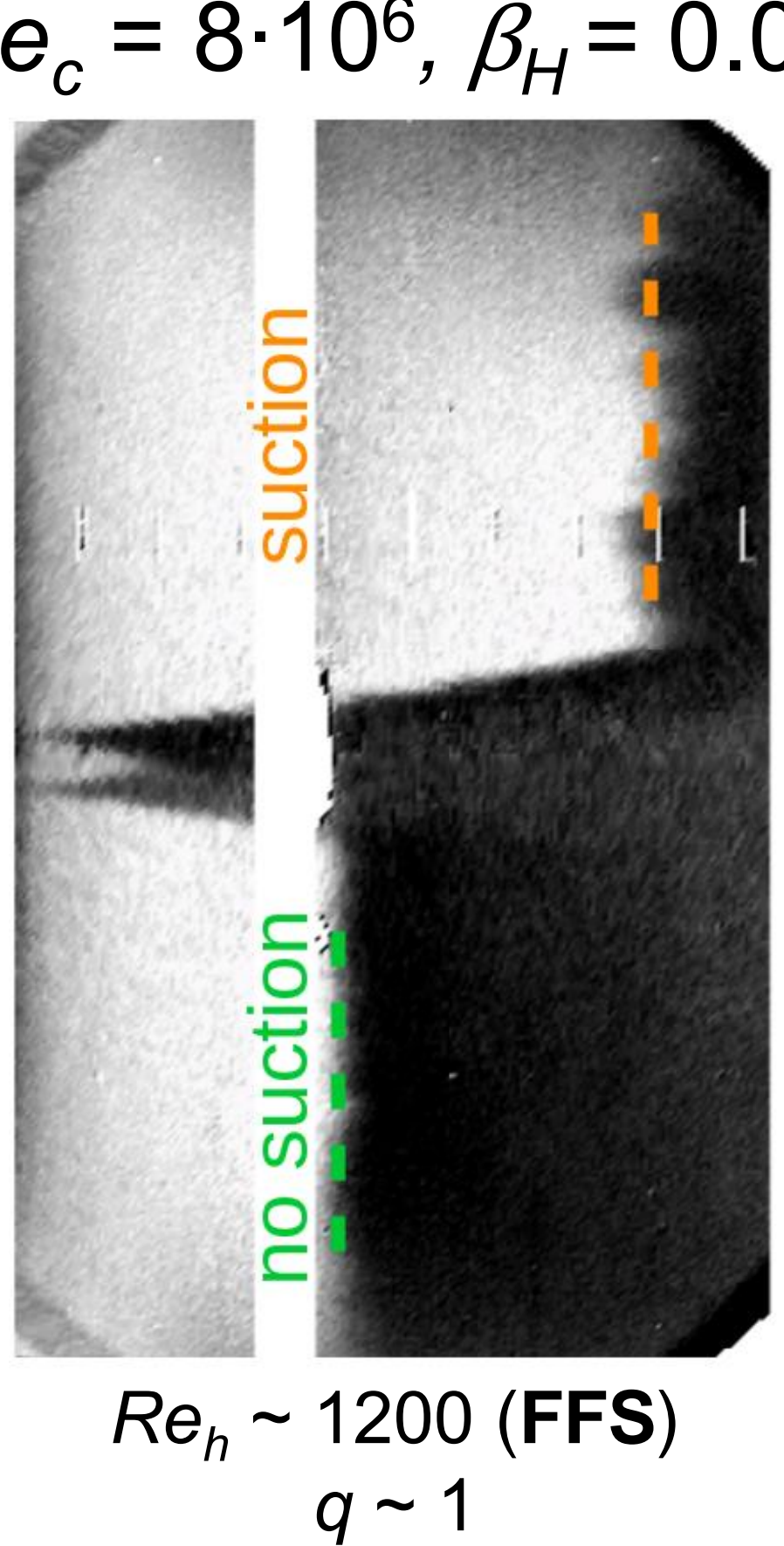

Suction

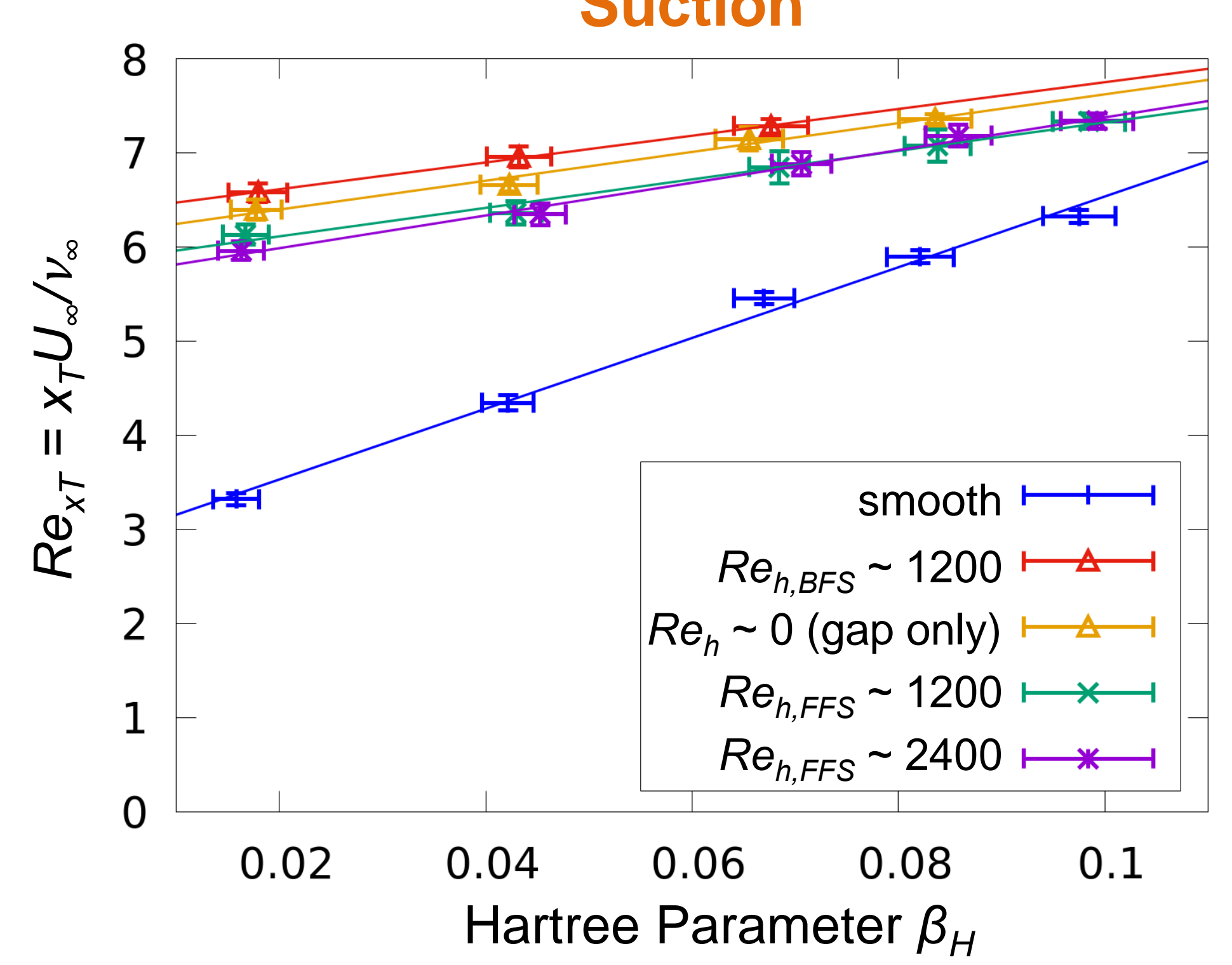

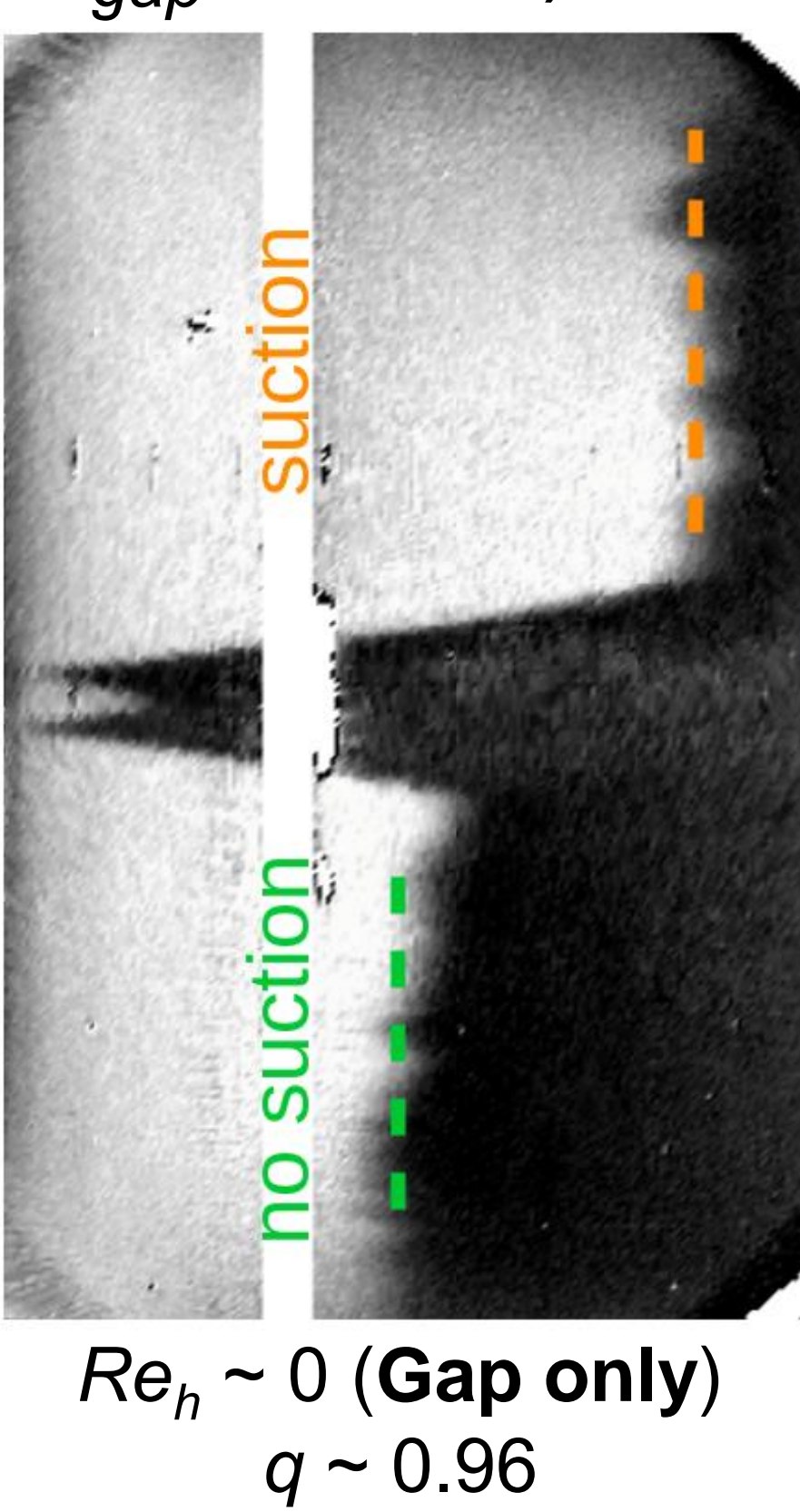

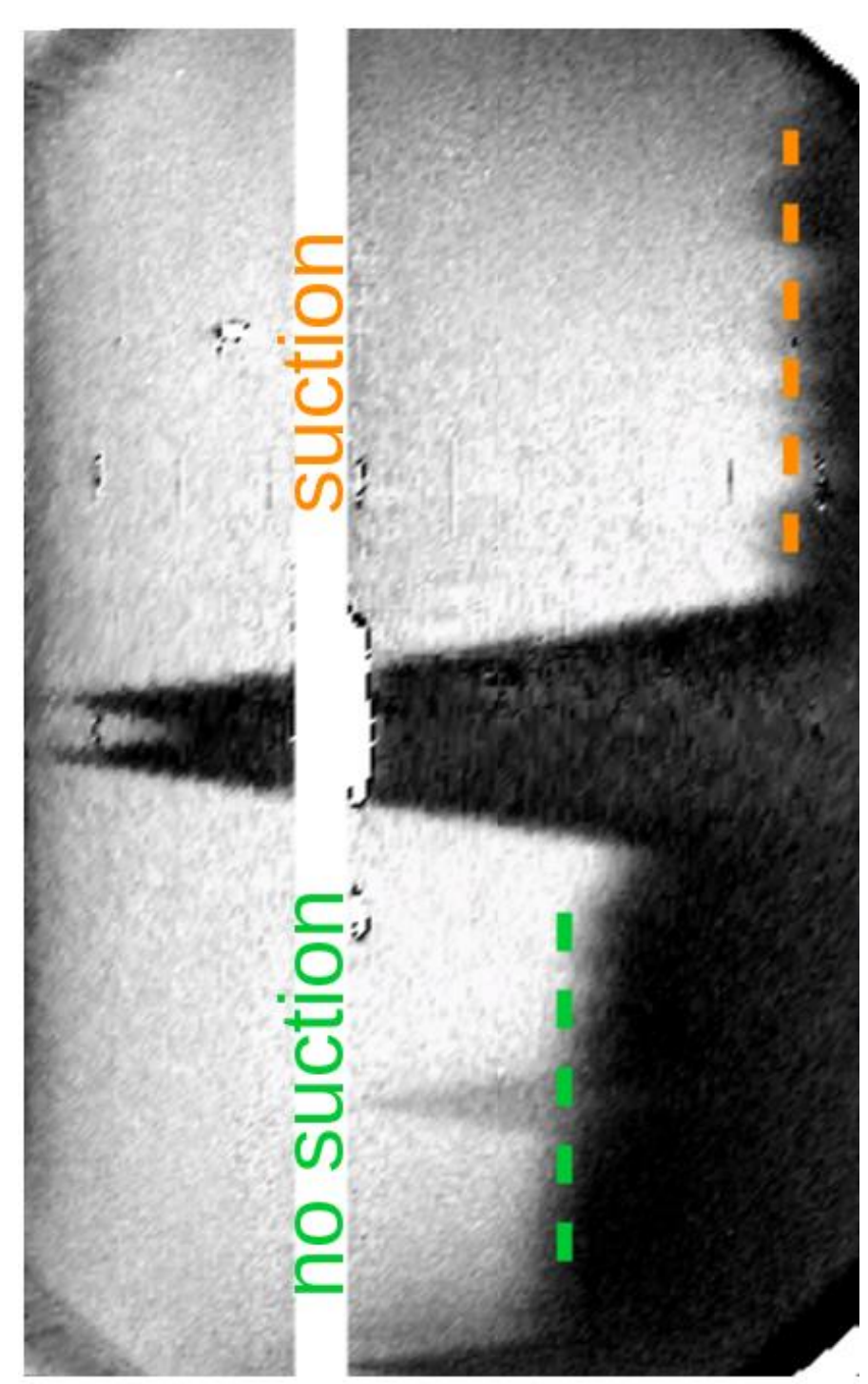

$R e_{h} \sim 1200($ BFS $)$ $q \sim 0.62$

(Transition with no suction influenced by internal gap flow)

Suction rate $q=\frac{v \cdot d_{\text {gap }}}{\delta^{*} \cdot U_{\infty}}$ with average suction velocity $v$, gap width $d_{\text {gap }}$, displacement thickness $\delta^{*}$ and freestream velocity $U_{\infty}$.

Transition Reynolds number with freestream viscosity $v_{\infty}$ as function of Hartree parameter for $R e_{c}=8 \cdot 10^{6}$ and $M=0.6$.

\section{Conclusions}

- Varying step heights $(-30,0,30,60 \mu \mathrm{m})$ in combination with a streamwise gap and a smooth configuration were examined for laminar-turbulent transition location by means of TSP.

- Suction significantly delays transition and even overcompensates the adverse effect of step and gap.

- For no-step and backward-facing step configurations, transition location was detected further downstream despite considerably lower suction rates. 